\title{
Epilepsy, Stigmatization and Media Campaigns: An Assessment of Rise Clinic Experience
}

\author{
Malachy Chukwunonso Onyema (Ms.C) ${ }^{1}$, Ms. Uzoamaka Onyinye Ikegwuonu- \\ Chukwueloka (Ms.C) ${ }^{2}$ \\ ${ }^{1}$ Lecturer, Wellspring University, Benin City, Nigeria \\ ${ }^{2}$ Manager Rise Clinic, Participant, Nigeria Epilepsy Care Advanced Programme (NECAP)
}

\begin{abstract}
Stigmatization associated with health related cases is often a challenge in health management. A person is stigmatized when he or she is a carrier of a dangerous disease such as HIV or Ebola. Epilepsy is a brain disorder that is symptomatic with seizures but the knowledge about the disease is always twisted with cultural mythology especially here in Nigeria. The study which was inspired by The Nigeria Epilepsy Care Advance Programme (NECAP) is set to determine patterns of media exposure on campaigns against epilepsy; impact of media campaign in seeking medical assistance; impact of media campaign in understanding epilepsy as a public health concern and to establish stigmatization as a threat to epileptic patients in social and cultural activities in the society. In-depth interviews were granted to 30 epileptic patients registered in RISE Clinic NECAP program. Also 400 non-epileptic persons were surveyed across the three senatorial zones using simple random sampling. It was discovered that there is poor media campaign against epilepsy and epileptic patients are usually stigmatized in our society. Therefore, government and nongovernmental organizations through the media should embark on public education and enlightenment.
\end{abstract}

Keywords: Epilepsy, Stigmatization, Culture, Health Communication, Media Campaign, NECAP

\section{BACKGROUND OF STUDY}

Epilepsy is a disorder of the brain characterized by an enduring predisposition to generate epileptic seizures. The definition of epilepsy requires the occurrence of at least one epileptic seizure (Fisher, Boas, Blume, Elger, Genton, Lee \& Engel Jr., 2005).

The main thrust of epilepsy communication interventions is to combat stigma. "Misinformation and misconceptions about epilepsy appear to be the main issues working against the improvement of quality of life for epileptic people". (Bandstra \& Camfield 2008)

One way to combat stigma and assist epileptic people towards a better life, is creating awareness through media campaigns. This study therefore seeks to verify whether media campaigns have been effective in facilitating the goals of the Nigerian Epilepsy Care Advancement Programme (NECAP), through the activities of RISE Clinic Adazi-Ani, Anambra State, Nigeria.

Historically, epilepsy in many cultures in Nigeria is believed to be a sacred disease and this has remains a major challenge against discrimination. People in Nugeria see patients experiencing seizures as a manifest of evil spirit. "Epileptic seizures have been known as the only symptom of epilepsy. Seizure is the synchronized electrical discharge from the brain - a normal brain function that just keeps going" (Scambler \& Hopkins 2006).

Also, Atadzhanov et al (2010) reports that "seizures during cooking with open fires often lead to burns; a prospective study in South Africa showed that 50\% of the adults admitted with burns had epilepsy. Scars, especially on the face, are visible to other people and lead to shame and discrimination and people see burns as a seal of the victim's fate, as said by traditional healers in Zambia" (p. 12).

I have encountered an epileptic patient, convulsing and shaking violently and the experience was horrible and I began to imagine the public disgrace they might be passing through. The stigma associated with the ailment is as a result of the myth surrounding it. It seems that some people believe that the disease is contagious through an infected person's sweat, saliva or underwear. It also appears 
that some people believe that epilepsy is as a result of supernatural curses from the gods and these have hampered the treatment of epilepsy in Nigeria.

Mbuba, Ngugi, Newton, Carter (2008) "People with Epilepsy (PWE) in Africa are disabled by stigma. A combination of traditional beliefs, poverty, lack of medical care, and inability to fulfil their social roles has a negative impact on the lives of PWE. Stigma is not only felt by PWE, courtesy stigma is the 'stigma by association' experienced by people close to someone who is stigmatised" (p.3).

Atadzhanov, Haworth, Chomba, Mbewe, Birbeck (2010) reports that in Europe, "a three-question tool has been designed to assess the level of patient-perceived stigma, and this scale has also been used in Zambia. People are asked if they feel like other people, because of their epilepsy: (1) are uncomfortable with them, (2) treat them as inferior, or (3) prefer to avoid them, with a total score of 0-3.7" (p. 9).

Shibre, Alem, Tekle-Haimanot (2008) opined that:

one aspect influencing stigma is that many people in Africa believe epilepsy to be contagious and that it can be spread by urine, saliva, flatus, or faeces excreted at all times or during a convulsion. This can result in isolation and unwillingness of witnesses to touch the patient and protect from injury during a seizure. Among 170 PWE, stigma was experienced most by people reporting contagious beliefs of themselves or their neighbourhood and in people with a forced disclosure (p. 13).

Shibre (2008) reports that "the belief that seizures are a sign of bewitchment leads to stigma too and PWE will seek care from traditional healers who often emphasise these beliefs and medical care is delayed. In a door-to-door study in Zambia fewer than 4\% of PWE had sought medical care while all had been to a traditional healer" (p. 6).

Berhanu \& Prevett (2004) presents that "as a consequence of the seizures and the related stigma PWE might be unable to find a partner or are at risk of abandonment after disclosure. Anti-marriage laws were introduced in some countries over 200 years ago, even in England this law was not repealed until 1970" (p. 15).

Atadzhanov et al (2010) reported that:

Because of discrimination or physical disabilities some PWE even face problems with basic needs like food. During a famine in southern Zambia, PWE had significant weight-loss and some reported they were excluded from food distributions. Roles in the community cannot be fulfilled, resulting in loss of status or income. Of 1250 inhabitants of rural Ethiopia $46 \%$ responded that they would not employ an epileptic. Resulting poverty might lead to limited access to healthcare.

There have been public campaigns on epilepsy management and treatment around the world since 1997 by the three reputable and leading organizations - International League Against Epilepsy (ILAE), International Bureau for Epilepsy (IBE) and World Health Organization (WHO). In order to pursue their aims in improving better general awareness, the collaboration among these organizations has been reinforced and reoriented by the launch of the Global Campaign Against Epilepsy (GCAE). The mission statement of the campaign is: "To improve acceptability, treatment, services and prevention of epilepsy worldwide" (ILAE/IBE/WHO Global Campaign against Epilepsy 2004). They discussed the treatment gap (TG) and they accepted the following definition: 'The difference between the number of people with active epilepsy and the number whose seizures are being appropriately treated in a given population at a given point of time, expressed as percentage. This definition includes diagnostic and therapeutic deficits.' The general activities of the global campaign include; collaboration to increase awareness about epilepsy, regional conferences and declarations, regional reports and country resources, technical consultative meetings. A number of public campaign projects have so far been developed in some countries like Zimbabwe, Argentina, Brazil, China, Pakistan and Senegal with the aim of improving epilepsy care for the development of a successful model of epilepsy care through the national, regional and a global health care systems. 
Whether the Global Campaigns Against Epilepsy (GCAE) launched by the 3 organizations are successful and provide suitable approaches for other countries to adopt will have to be confirmed by evidence. Their success or otherwise will be seen in terms of the decrease of the treatment gap and its consequences in the campaign region. In order to discern whether a campaign is achieving the desired results, its performance will be specifically measured by comparing the following:

- The number of people with epilepsy who received a correct diagnosis;

- The number of people who sought medical intervention;

- The social situation of people of various age groups with epilepsy

- Knowledge, attitudes and practice of those interviewed at the onset.

Health campaigns are now a paramount factor in advancing health messages and to actualize health positive objectives. Communication forms the backbone of health campaign and the Nigerian Epilepsy Care Advancement Programme (NECAP) launched by RISE Clinic Adazi-Ani, Anambra State employed this initiative in its campaign against epilepsy in Nigeria.

The main goal of NECAP is to improve epilepsy care through the creation of sustainable epilepsy clinics and programs targeting three main barriers to epilepsy care identified in Nigeria. These barriers include: Lack of disease awareness; Lack of proper treatment and follow-up; and limitations in skills and knowledge sets of local care givers.

\section{Statement of Research Problem}

Epilepsy is a major public health issue, especially in developing African countries. It appears to be one of the oldest conditions known to mankind, and yet there is still so much misinformation, stigma and negativity associated with the disorder (Kristin, 2012).

However, stigma is a bane in the treatment of this disease. People living with epilepsy are often denied some socio cultural privileges and the symptoms are often refer to as demonic manifestation. Often times, epileptic patients are taken to pastors for prayers, healing and deliverance. This can be ascribed to having insufficient knowledge about the disease.

People who have been diagnosed with epilepsy could suffer from possible loss of self-confidence and anxiety about recurring epileptic fits. The major psychosocial burden of epilepsy is stigma which has no boundaries and occurs across all ethnic, gender, educational, and socioeconomic groups, often leading to discrimination ( Bateman, Begley, Ben-Menachem, Berg, Berkovic, Cascino, Drazkowski, Edwards, Engel, Jr., French, Gilliam, Hoerth, Jehi, Kanner, Krauss, Labiner, Loddenkemper, Luders, McKhann, II, McLachlan, Modi, Pennell, Shafer, Sirven, Stern, Szaflarski \& Theodore, 2012).

One way to combat stigma and assist epileptic people towards a better life, is creating awareness through media campaigns. It would appear that only by frequent, rapid, repetitive, and effective education and the recognition and reconciliation of institutionalized stigma can there be a reversal of the downward spiral of epilepsy (CDC Report, 2012). The need therefore, arises to establish the epilepsy picture in Nigeria; the issue of stigmatization of people with epilepsy and the impact of communication interventions.

\section{OBJECTIVES OF STUDY}

The specific objectives are:

- To ascertain if epileptic patients are exposed to media campaigns against epilepsy.

- To determine if exposure to media campaigns against epilepsy motivates epileptic patients to seek medical help.

- To find out if people not suffering from epilepsy are exposed to media campaigns against epilepsy.

- To ascertain if exposure to media campaigns against epilepsy improves the understanding of the issue of epilepsy among members of the community.

- To ascertain if there is stigmatization against epileptic patients. 


\section{RESEARCH QUESTIONS}

To measure the variables for the study, the research objectives were transformed into research questions:

- What numbers of epileptic patients are exposed to media campaigns against epilepsy?

- Who among the epileptic patients seek medical help after exposure to media campaigns against epilepsy?

- What numbers of individuals who are not epileptic patients are exposed to campaign against epilepsy?

- What numbers of individuals who are not epileptic patients understand the issue of epilepsy through media campaign?

- What numbers of individuals who are not epileptic patients engage in stigmatization against epileptic patients?

\section{SCOPE OF STUDY}

The study focuses on epileptic patients and non-epileptic individuals' responsiveness to information on epilepsy.

The study dwells on patients who responded to media campaigns for treatment in Anambra State and it is expected that epileptic patients from all the towns in Anambra state, Nigeria will respond to the message.

Similarly, the target audience in this study are epileptic patients and non-epileptic members of the public in Anambra State within the age bracket (16-60yrs and above).

\section{Literature REVIEW}

\subsection{Epilepsy in Nigeria}

Preux and Druet (2005) noted that $80 \%$ of the people affected with epilepsy live in developing countries, especially the sub-Saharan African region; two thirds of these populations were children under the age of 15 . Those affected by epilepsy are more likely to live in poor living conditions and have low income levels. Preux and Druet claimed that only $46.4 \%$ of persons with epilepsy had access to drinking water and 55\% had access to solid waste management (i.e., toilets and pit latrines). These poor living conditions make it easy for parasitic and bacterial transmission to occur.

Epilepsy in Nigeria is seen as a source of stigma and misery for sufferers due to negative and incorrect knowledge of the disease and even occasional seizures which may have serious personal and societal consequences. This disease is associated with socioeconomic effects. Epilepsy is seen as the most common neurological disorder. The day to day consequences of epilepsy in developing countries like Nigeria includes loss or change of job, a reduction in social interaction and productivity and physical effect of frequent seizures which make it difficult to attend to school, work or social functions. Some studies have shown that epilepsy affects the intellectual abilities of PWE.

In a study by ILAE 2004, cultural and religious beliefs are important issues in the management of epilepsy which influence the value being placed by the society on chronic disorders like Epilepsy. Local beliefs are seen as the causes of epilepsy which create the reasons why most patients seek advice from traditional rulers and healers.

In a research by Akinsulore \& Adewuya (2010) psychosocial aspects of epilepsy in Nigeria with the use of PUBMED database reviewed that the prevalence of epilepsy varies from 5.3 to 37 per 1000 in Nigeria, the patients suffer social deprivation and discrimination in education, employment, housing, marital life as well as associated psychiatry morbidity and has a significant impact on the day to day functioning of persons with the disorder.

Udoh, C. C. (2006) conducted a study on pattern and presentation of epilepsy in Enugu. The study revealed most affected patients were aged from 15-34 years with the use of 207 patients, 113 males and 94 females, 22\% had childhood seizures approximately and $88 \%$ had convulsive seizures. Monotherapy was used in $89 \%$ of patients, with $71 \%$ having good control. Alcohol use and head injury were seizure risks in $12 \%$ and $20 \%$ of patients. 


\subsection{The Prevalence and Incidence Rates of Epilepsy in Nigeria}

The prevalence rate of epilepsy in Nigeria is estimated to be around eight to 13 per 1,000 persons (Kabir, lliyasa, Abu-Bakr, Kabir, \& Farinyaro, 2005). The prevalence rate of epilepsy in the urban cities like Lagos is similar to those in rural villages, with 13 to 37 per 1,000 persons having epilepsy (Olumbini, 2006). One remedy used by traditional doctors and herbalists to treat individuals with epilepsy is to beat them with canes in an attempt to drive away evil spirits. This observation was reported by many researchers who carried out studies on epilepsy in Liberia, Ghana, and Senegal (Kabir et al., 2005). Patients and their families are isolated from other community members. This isolation caused more stigma and neglect of persons with epilepsy, thereby increasing their chance of deterioration and decreasing the possibility of improvement in their condition, adding to the risk factors that affect their daily quality of life.

Table 1. Prevalence of epilepsy in Nigeria and other African countries

\begin{tabular}{|l|l|l|}
\hline \multicolumn{1}{|c|}{ Country/Location } & \multicolumn{1}{|c|}{ Prevalence Rates/1000 } & \multicolumn{1}{c|}{ Investigator } \\
\hline Congo & 4 & Piraux (1960) \\
\hline South Africa & 4 & Bird et al (1962) \\
\hline Ghana & 4 & Haddock (1973) \\
\hline Uganda & 4 & Orley (1970) \\
\hline Zimbabwe & 7.4 & Levy et al (1964) \\
\hline Ethiopia (Rural) & 8 & Giel (1968) \\
\hline Ethiopia (Urban) & 5 & Giel (1968) \\
\hline Senegal & $3-8$ & Collomb et al (1970) \\
\hline Tanzania & 1 & Smartt (1959) \\
\hline Tanzania & 20 & Jilek \& Jilek (1970) \\
\hline Kenya & $10-18$ & Miyangi (1995) \\
\hline Nigeria (Urban) & $8-13$ & Dada (1970) \\
\hline Nigeria (Rural) & 5.3 & Osuntokun(1987) \\
\hline Nigeria (Rural) & 6.2 & Longe and Osuntokun(1989) \\
\hline
\end{tabular}

Source: Epilepsy in Nigeria - a review of etiology, epidemiology and management by Olubunmi, A. Ogunrin

\section{NECAP}

The Nigeria Epilepsy Care Advance Programme (NECAP) is a counter-part support programme from Ministry of Health Anambra State, RISE Clinic and Sutter Health (East Bay Neurosurgical Institute) North California to further campaign against epilepsy and to offer medication for affected epileptic patients.

The problem of stigmatization has made people living with epilepsy to distance from medical consultations and treatments.

NECAP is charged to improve acceptability, treatment, education, sensitization and prevention of epilepsy worldwide.

NECAP adopted the following models for treatment of epilepsy to include:

- Publicise availability of treatment.

- Educate patients and staff.

- Improve patients' life style.

- Adequate supplies of drugs.

- No charges on medications.

- Monthly review clinics.

\subsection{Epilepsy and Issue of Stigmatization}

Stigma is a major concern that represents an overwhelming proportion of the psychosocial burden of epilepsy. Stigma knows no boundaries and occurs across all ethnic, gender, educational, and socioeconomic groups, leading to discrimination. Only by frequent, rapid, repetitive, and effective education and the recognition and reconciliation of institutionalized stigma can the downward spiral of epilepsy be reversed. Stigma and social discrimination in relation to epilepsy may be associated with a lack of knowledge and understanding about the condition. 
Epilepsy is neither contagious nor infectious, but some people with epilepsy are discriminated against in education, marriages, and employment due to the belief that epilepsy is highly contagious. Some patients have reported that their wives left them with the children due to enuresis or bedwetting that occurred during seizure activity (Baskind \& Brubeck, 2005). In some countries, people with epilepsy cannot eat with the same utensils as people who do not have epilepsy and some cannot be buried in the family grave (Baskind et al., 2005). The stigma of epilepsy has led some people with epilepsy to conceal their disorder due to shame and to avoid being isolated from peers and close friends. This has led some adolescents with epilepsy into depressive and psychotic moods/behavior and has delayed early treatment (Paschal, Hawley, Romaine, Low, Mudguard, Sly, \& Sadler, 2007).

People with disabilities are among the most vulnerable in any society. This vulnerability is even greater among those with hidden disabilities such as epilepsy and other neurological conditions and intellectual disabilities. Although, the vulnerability of people living with epilepsy may be partly attributed to the disorder itself, all chronic medical conditions have an impact on daily life, but the impact of epilepsy is greater; the particular stigma associated with epilepsy brings as susceptibility of its own. Stigmatization leads to discrimination, and people with epilepsy have been the target of prejudicial behavior in many spheres of life, over many centuries and in many cultures (Pahl \& Bore, 2005, p.72).

\subsection{Epilepsy and the Issue of Medical Assistance}

Some of the known causes of epilepsy are infections, fever of unknown origin, cerebral malaria, tapeworms in the brain, injuries sustained during birth, intracranial infections of bacterial or viral origin, prenatal brain damage, toxic agents, and hereditary factors (Paschal et al., 2007). Some scholars have identified tuberous sclerosis as a cause of epilepsy noted in early stage as infantile spasm (Petrova, 2011). Acute seizures are common in severe meningitis, viral encephalitis, malaria, and neurocysticercosis, and are associated with increased mortality and morbidity (Singh, 2011).

Although researchers have revealed that most of the people affected with epilepsy worldwide live in developing countries, some of these individuals do not receive treatments. The negative attitude towards people with epilepsy, along with the increased stigmatization, widens the treatment gap as the affected individual hides his or her illness and does not seek adequate treatment (Meyer et al., 2010) in Maduakor-Ugo (2014). The treatment gap in 46 developing countries originates from (a) both social and cultural factors related to cultural beliefs regarding epilepsy's causes and treatment, (a) a lack of knowledge and understanding about epilepsy, (c) a lack of medical staff and access to care, and (d) economic factors such as distance to certain health facilities and supply of drugs (Chisholm, 2005) in Maduakor-Ugo (2014). Natives of developing countries may first consult traditional healers and high priests for treatment before seeking medical care due to a lack of knowledge and treatment of epilepsy.

The global campaign against Epilepsy, Epilepsy Out of the Shadows, was launched as a joint effort by the International League Against Epilepsy, the WHO, and the International Bureau for Epilepsy to bridge the treatment gap (WHO, 2004). The purpose of this global campaign was to help developing countries reduce the burden of epilepsy by increasing access to care and provide oral treatment such as phenobarbital which is the cheapest medication for seizure disorder, followed by tegretol and dilantin (WHO, 2004). Providing access to care in developing countries would reduce epilepsy risk factors and be helpful in reducing the burden of epilepsy. Epilepsy affects people of all ages, gender, and social classes and has no geographical boundary.

The CDC recognized epilepsy as a public health issue within the last 15 years. There are various methods of treatment for epilepsy, which include traditional Western treatment with oral therapy, surgery Vagus nerve stimulation, and the use of the ketogenic diet (Epilepsy Foundation, 2010).

Some of these methods of treatments used in industrialized countries are available in some developing countries such as Nigeria but mostly in urban cities of Lagos, Ibadan, Enugu, and Port Harcourt. The poor in remote areas cannot afford to cover transportation to and from the interior village to urban city hospitals and pay hospital bills. More than $80 \%$ of patients with new onset of seizures in the United States are treated by general practitioners who are not likely to be aware of new diagnostic and therapeutic measures. Health care professionals, as well as teachers, patients, caregivers, and the general population, are in need of education regarding epilepsy (Schneider \& Conrad, 2009, p.19). 


\subsection{Media Campaigns against Epilepsy and Patients' Response}

The NECAP-RISE epilepsy campaign is built to ensure adequate health treatment and access for epileptic patients. The campaign is yielding lots of gains as patients responded to treatments at RISE clinic which is the main center for epileptic patients.

People with epilepsy suffer not only from lack of appropriate care, but also stigma and discrimination resulting from widespread prejudice and ignorance. To fight this plague reaching out to the general public is as important as educating health personnel.

Health communication has been defined as "the main currency of health care in this $21^{\text {st }}$ century" (Clansey, 2004 in Schiavo, 2007, p. 7). Without communication, health care delivery will be poor and inadequate.

The mass media are pivotal tools in disseminating health information. Health media campaigns are belted on communication protocols to ensure awareness, education and enlightenment.

According to Sparks (2012)

Mass media campaigns are widely used to expose high proportions of large populations to messages through routine uses of existing media, such as television, radio, and newspapers. Exposure to such messages is, therefore, generally passive. Such campaigns are frequently competing with factors, such as pervasive product marketing, powerful social norms, and behaviours driven by addiction or habit. In this review we discuss the outcomes of mass media campaigns in the context of various health-risk behaviours (e.g., use of tobacco, alcohol, and other drugs, heart disease risk factors, sex-related behaviours, road safety, cancer screening and prevention, child survival, and organ or blood donation) (p. 6).

We can agree that mass media campaigns can produce positive changes or prevent negative changes in health-related behaviours across large populations.

Sparks (2012) also affirms that "over the past few decades, media campaigns have been used in an attempt to affect various health behaviours in mass populations. Such campaigns have most notably been aimed at tobacco use and heart disease prevention, but have also addressed alcohol and illicit drug use, cancer screening and prevention, sex-related behaviours, child survival, and many other health-related issues" (p. 10).

Typical campaigns have placed messages in media that reach large audiences, most frequently via television or radio, but also outdoor media, such as billboards and posters, and print media, such as magazines and newspapers. Lancet (2010) similarly opines that "exposure to such messages is generally passive, resulting from an incidental effect of routine use of media" (p. 3).

However, the inceptions of new technologies that are internet borne are now a viable tool in most campaign strategies. The NECAP-RISE epilepsy campaign did not ignore this development as ads were made available in RISE clinic websites, blogs, Facebook, twitter and Google+ accounts.

Media campaigns against epilepsy can be of short duration or may extend over long periods. They may stand alone or be linked to other organised programme components, such as clinical or institutional outreach and easy access to newly available or existing services, or may complement policy changes. Multiple methods of dissemination might be used if health campaigns are part of broader social marketing programmes.

The profound utility of the mass media campaigns against epilepsy lay in their ability to disseminate well defined behaviourally focused messages to a large audience over a time as the campaign elapses according to its design.

According to Lancet (2010), the following are the objectives of mass media campaigns:

- Mobilising and supporting local agencies and professionals who have direct access to individuals within the target population

- Bringing together partnerships of public, voluntary and private sector bodies and professional organisations 
- Informing and educating the public, but also setting the agenda for public debate about the health topic, thereby modifying the climate of opinion surrounding it

- Encouraging local and national policy changes so as to create a supportive environment within which people are more able to change their behaviour (para. 27).

Media campaigns against epilepsy are generally aimed primarily to change knowledge, awareness and attitudes of patients with epilepsy (PWE) and contributing to the goal of changing patterns of their behaviour.

\subsection{General Public Response to Media Campaigns against Epilepsy}

Media campaigns as an intervention tool is designed to engage in the mitigation of stigma.

Efforts to increase public awareness and knowledge are motivated by the expectation that information that reduces misconceptions and misinformation will improve attitudes and, ultimately, behavior toward people with epilepsy and thereby reduce stigma. Stigma, whether felt or overtly experienced, has many negative consequences for both health and quality of life, and overcoming it is an important goal for the field.

For the public in general, the news and entertainment media are significant sources of health information. Unfortunately, inaccurate depictions of people with epilepsy and of severe seizures, used for dramatic effect, reinforce negative perceptions. Clear messages conveyed through multiple forms of media, including social media and the Internet, along with diverse educational activities targeted to specific audiences, are necessary for successful stigma reduction and public awareness efforts. Any such efforts, local or national, should take into account the health literacy and cultural characteristics of target audiences, with different strategies developed for reaching each audience.

Many people have fears of not wanting to associate with people with epilepsy because they fear not knowing what to do when a person has a seizure. The Center for Disease Control and Prevention (CDC; 2011) created a first aid video for seizures, explaining what care is expected when someone is having seizure activity, to remain calm, to take control, to ease the person to the floor if needed, and to remove dangerous elements for safety. In the video, testimonials were given by people with epilepsy. This video was used to demonstrate that epilepsy should not affect a person's quality of life.

Media campaigns had been the major weapon in fighting any type of stigma, and as such Hills (2010) used educational strategies to convince the population of New Zealand that direct contact with people with epilepsy alleviated fear and was proven to be successful. Most of the families including teenagers, children of people with epilepsy, and those who did not have epilepsy bonded well during outings. Activities such as biking, barbecuing, and kiting on National Kite Day helped to change the way people perceived epilepsy (Hills, 2010).

Oarhe and Aghedo (2010) organized self-help groups that engaged in organizing outdoor activities like moonlight dances in some of the village squares in which interested villagers were encouraged to participate in addition to the teaching programs. Activities such as storytelling, roasting corn, and watching masquerades with people diagnosed with epilepsy and those without epilepsy joined with their families would encourage and increase bonding and direct contact (Oarhe \& Aghedo, 2010). The best way to fight stigma both in developed and developing countries is through media campaigns intervention.

\subsection{The Impact of Media Campaigns in Enhancing Inclination to Seek Medical Help among Epileptic Patients.}

Research consistently demonstrates that many people with epilepsy do not have a solid understanding of basic information about their condition how it is diagnosed, seizure precipitants or triggers, types of seizures, the purpose and potential side effects of seizure medications, safety concerns, and the risks and potential consequences of seizures.

A pilot study is an initial study carried out before the main study to evaluate the effectiveness of the research questions or questionnaires, Paschal et al. (2007) conducted a community-based study with 165 participants in which a pilot study was done with three participants. The patient perceptions gathered provided a step in determining means for overcoming stigma related to epilepsy in this community (Paschal et al., 2007). A 48-item questionnaire was used and divided into sections. The 
three patients involved in the pilot study suggested using epilepsy letterhead and envelopes because patients would respond more to their physician's survey compared to a survey by other groups or researchers (Paschal et al., 2007). Paschal et al. found that that 59\% of the participants indicated that information in doctors' offices would be the best method to increase awareness of epilepsy among people with epilepsy and their caregivers. Forty-two percent of the participants indicated using educational pamphlets and television advertisements, 29\% indicated using a community epilepsy nurse, 24\% indicated using radio announcements, and 21\% indicated using extension services or agents as the best way to increase awareness among epilepsy patients. The use of television ads was ranked as the best way to educate the general public and information in doctors' offices was the second most commonly indicated choice. The reverse was chosen for educating patients. Information in doctors' offices was most commonly indicated as the best educational method and television campaigns were the second most commonly indicated choice (Paschal et al., 2007).

There is a need for media campaigns as an intervention to increase general public awareness related to epilepsy knowledge, attitude, and information on treatment options, thereby reducing the level of stigma associated with epilepsy. Cultural and ethnic misconceptions of epilepsy have resulted in increased stigma perceived by people with epilepsy (Olumbini, 2006). Researchers have examined the effect of stigmatization on the quality of the lives of people with epilepsy in relation to education, employment, socialization, and other aspects of their daily living.

\subsection{The Impact of Media Campaigns in Making the General Public More Accommodating towards Epileptic Patients.}

Public campaign plans to increase awareness of epilepsy have been somewhat effective in decreasing stigma. This could be attributed to an aggressive global campaign against epilepsy stigma by the WHO to reduce the burden of those affected by epilepsy worldwide (WHO, 2004).

Paschal et al. (2007) studied the types of information that should be promoted in an epilepsy campaign for the general public and confirmed that "information about reactions to seizures" was topranked by 59\% of respondents. Paschal et al. claimed that 58\% of participants top-ranked "general information about epilepsy," and 43\% indicated the same for "information about reactions to epilepsy"; $42 \%$ of respondents ranked "information about supporting epilepsy patients" as the most important type of information (p. 322). Thirty-two percent of respondents indicated that "information about origins of epilepsy" was the most important type of information to promote in an epilepsy awareness campaign for the general public (Paschal et al., 2007, p.332). The public should be provided with information on the causes of epilepsy, manifestation, complications, and treatment options to increase epilepsy awareness and stigma reduction.

Rogers and Storey (1987) in French (2004) observe that in the modern communication campaign, "modest changes in audience behaviour are frequently achievable, and it is important for the campaign planner to set modest and realistic expectations about what can be achieved" (p. 9).

French (supra) argue that a "health promotion campaign might be considered successful or effective if about five percent of the target (or segmented) audience does adopt measurable changes in health behaviour over the longer-term".

It should be noted that the word communication is used to highlight the fact that not all campaigns necessarily involve mass media messages, or mass media messages in isolation, and that communication campaigns may be small-scale in scope and audience reach.

There is often confusion between the labels campaign, communication campaign or program, media or mass media campaign, and intervention.

Rogers and Storey (1978) in French (2004) argue that "no particular definition adequately covers current practice, and there are many local variations of what is meant by these labels. Indeed, a variety of definitions exists in the literature but the following elements of a communication campaign are essential" (p. 16)

French (2004) stipulated the following as objectives of health communication messages

- Firstly, a campaign is purposive. The specific outcomes can be extremely diverse ranging from individual level cognitive effects to societal or structural change.

- Secondly, a communication campaign is aimed at a large audience. Rogers and Storey in French (2004) note that 'large' is used to distinguish campaigns from interpersonal persuasive 
communications by one individual (or a few people) aiming to seek to influence only a few others.

- Thirdly, communication campaigns have a specified time limit. This is not to state that all campaigns are short lived.

- The fourth point is that a communication campaign comprises a designed set of organised activities. This is most evident in message design and distribution (p. 21).

Rogers and Storey (1987) in French (2004) supports the following roles as generalization that presents guidelines for a successful health media campaign:

- Widespread exposure to campaign messages is a necessary ingredient in a campaign's success.

- The mass media can play an important role in creating awareness and knowledge, in stimulating interpersonal communication, and in recruiting individuals to participate in campaign activities.

- Interpersonal communication through peer networks is very important in leading to and maintaining behaviour change.

- The perceived credibility of a communication source or channel enhances the effectiveness of a communication campaign.

- Formative evaluation is as important as summative evaluation following the conclusion of the campaign. Formative research involves evaluating aspects of the campaign, especially message design and audiences understandings, in the planning stages. This work can improve the effectiveness of campaigns by producing messages that are specific to the desired behavioural change.

- Campaign appeals that are socially distant from audiences are not effective.

- Campaigns promoting prevention are less likely to be successful than those with immediate positive consequences.

- Audience segmentation strategies can improve campaign effectiveness by targeting specific messages to particular audiences.

- Timeliness and accessibility of media and interpersonal messages can contribute to a campaign's success (p. 57)

Similarly, Bauman (2000) in Tones, K and Green, J (2004) offers a set of guidelines, which he characterises as precepts and principles for campaign planners. These are focused on best practice and grounded in both campaign experience and evaluations of mass media health campaigns. Bauman (2000) presents that "media campaigns from ad hoc health advocacy that may involve the mass media should be purposive and should have the following organised interventions:

- Message development should be an integral component of the campaign. As Rogers and Story (1987) note, formative research is as important, if not more important, than summative evaluations after a campaign.

- 'Process monitoring' (process evaluation) is essential. This involves detailed assessment of each part of the campaign's implementation, providing essential data on message production and dissemination, and audiences' responses.

- Development of appropriate outcomes is essential. As Bauman (2000) says: 'Campaign planners should be clearly focused on the exact outcomes that are feasible, achievable and measurable'.

- Measurement of carefully defined outcomes is essential (i.e. summative evaluation).

- Research designs should include adequate resources and methods to achieve useful campaign evaluation. As the earlier literature review of mental health literacy programs demonstrated, valid and useful evaluations are not always conducted.

- Bauman argues that, at a minimum, the evaluation budget (formative and summative) should be more than 15 per cent of the total budget.

- The 'hierarchy of effects' matrix developed by McGuire (1989) is a useful guide to planning media roles in a campaign. Briefly, McGuire proposed that only about 50 per cent of an audience 
will recall the media message, about half of those will understand the message, half again will accept it as relevant, half again will shift attitudes, half of those will adopt the new behaviour, half will trial it, and half again will maintain the new behaviour. Thus, the role of the mass media is more likely to be effective in increasing salience of a campaign message rather than achieving behavioural changes. As Rogers and Story (1987) in French (2004) note that long-term behavioural change induced by mass media messages alone is unlikely to be successful

- Mass media messages in isolation usually achieve little; therefore other supportive interventions are essential. These may involve direct, personal interventions. Rogers and Storey (1987) make similar observations in their review of the research literature. Effective mass media campaigns need to be supported by other direct interventions.

- Over-time monitoring of linked or similar campaigns is important in assessing the longer-term effectiveness of campaigns. It is important to determine whether repeated campaigns are achieving net gains, maintaining the status quo, having no effect, or in fact having a negative effect.

- Clear frameworks for evaluation should be set by both state and federal governments to remove or, at least, to reduce any day-to-day politics from evaluation and policy-making.

- Dissemination of campaign evaluation results is vital to enable others to learn from previous campaign successes and failures (p. 19).

Messages are organised in terms of both form and content, and responsibility is taken for selecting appropriate communication channels and media. As Rogers and Storey (1987) in French (2004) point out, even those campaigns whose nature or goal is emancipation or participation involve organised message production and distribution.

- In summary, the term communication campaign implies that:

- It is planned to generate specific outcomes;

- In a relatively large number of individuals;

- Within a specified time period; and

- Uses an organised set of communication activities.

Media campaigns is planned in a bid to make the general public more accommodating towards epileptic patients and if these campaign is successful, the attitude of the general public would change positively towards the people with epilepsy (PWE).

\section{EMPIRICAL Literature REVIEW}

Adowa, Ocean, and Okeniyi (2006) in Maduakor-Ugo (2014) conducted a study in western Nigeria to evaluate the school performance of adolescents with epilepsy. Adowa et al. recruited 73 subjects with epilepsy aged 12 through 18 and another 73 subjects without epilepsy aged 12 through 18 . All subjects came from different demographic backgrounds. The children were evaluated using the child's attitude illness scale instrument (CATIS) which showed how children and adolescents felt about their condition. Adowa et al. found that adolescents without epilepsy had better school performance than those with epilepsy. The adolescents with epilepsy from the middle socioeconomic class performed better than others with epilepsy from a low socioeconomic class (Adowa et al. 2006). Adowa et al. called for the use of education as an intervention to increase the knowledge of the community on epilepsy with the objective of eradicating the stigma attached to epilepsy.

Weiss (2006) conducted a program in East Timor to address and access the burden of epilepsy in this community. Weiss et al. found out that about $95 \%$ of people with epilepsy in the communities were untreated, despite the availability of antiepileptic medications in their communities. Most children with epilepsy from the community do not go to school due to stigma and humiliation. This was related to a lack of training in the diagnosis and management of epilepsy among general health care workers, coupled with their cultural beliefs that epilepsy was caused by evil spirits or curses and was not a physical health problem (Weiss 2006).

Roux (2009) in Maduakor-Ugo (2014) carried out a study using mixed methods to investigate teachers' knowledge and attitude about children with epilepsy. Roux examined 316 teachers' knowledge and attitude by using the methodology of Persons with epilepsy Scale followed with seven 
open-ended questions and interviews. Roux indicated that the teachers are knowledgeable on epilepsy with a good attitude. Knowledge was associated with the degree of stigmatization and attitude towards people with epilepsy. The descriptive analysis from their response, however, indicated a gap between the teachers' knowledge related to first aid, symptoms of epilepsy, and how epilepsy affects children's learning and behavior (Roux, 2009).

Atadzhanov, Haworth, Chomba, Mbewe, Birbeck (2010) revealed that:

In Zambia, several studies were done among different groups of people (teachers, clerics, policemen, traditional healers, and health workers) to describe their knowledge of epilepsy and attitude to PWE.8, 10, 17-20 In general these studies showed a lack of knowledge regarding causes and treatment. There are not many studies examining the effect of education on stigma (p. 6).

In reflection on the aforementioned studies, there is need for a more robust and intensive communication campaign for PWE. This requires the media as a vital organ for information, education and sensitization.

Atkin and Wallack (1990) in Halpern and Bates (2004) states that "some elements of the research literature explore the use of mass media by health professionals to influence audiences' understandings and knowledge of health issues" (p. 4).

\section{THEORETICAL FRAMEWORK}

The theory used to define this study is Health Belief Model. This theory belongs to cognitive theories that propose that a certain set of perceptions or beliefs will predict behaviour.

According to Schiavo (2007) the health belief model was originally intended to "explain why people did not participate in programs that could help them diagnose or prevent diseases.

The major assumption of this model is that in order to engage in healthy behaviours, intended audiences need to be aware of their risk for severe or life-threatening diseases and perceive that the benefits of behavior change outweigh potential barriers or other negative aspects of recommended actions.

Green and Kreuter (1999) in Schiavo (2007), "HBM is one of the first theories developed to explain the process of change in relation to health behaviour" (p. 39).

Health Belief model is also regarded by Corcoran (2007) as a stage process which assume that "the individual is not on a continuum (as they are in cognitive theories) but at a 'step' or 'stage'. Each step on the model is a move forward towards achieving the behaviour. Stage-step theories postulate that the individual goes through a process of change via a series of stages" (p. 8).

According to Corcoran (supra), Becker (1974) developed the health belief model (HBM) from the work of Rosenstock (1966). "This model can be used as a pattern to evaluate or influence individual behavioural change" (p. 20).

The model proposes that a person's behaviour can be predicted based on how vulnerable the individual considers themselves to be. 'Vulnerability' is expressed in the HBM through risk (perceived susceptibility) and the seriousness of consequences (severity). These two vulnerability variables need to be considered before a decision can take place. This means a person has to weigh up the costs/benefits or pros/cons of performing a behaviour.

Schiavo (2007) presents the following as key components of HBM:

- Perceived susceptibility: The individual's perception on whether he or she is at risk for contracting a specific illness or health problem. People believe that epilepsy is contagious and they avoid contacts with people living with epilepsy for fear of being infected.

- Perceived severity: The subjective feeling on whether the specific illness or health problem can be severe (for example, permanently impair physical or mental functions) or life threatening and therefore worthy of one's attention. People believe that epilepsy is not curable. They see it as a disease that is severe and eludes any form of medication. 
- Perceived benefits: The individual's perceptions of the advantages of adopting recommended actions that would eventually reduce the risk for disease severity, morbidity and mortality. People believe that health campaigns proffer solutions to their health problems and this induces people living with epilepsy to seek medical help because they believe it will help in reducing their recurring epileptic fits.

- Perceived barriers: The individual's perceptions of the costs of and obstacles to adopting recommended actions (includes economic costs as well as other kinds of lifestyle sacrifices). A combination of traditional beliefs, poverty, lack of medical care, and inability to fulfil their social roles has a negative impact on the lives of people with epilepsy.

- Cues to action: Public or social events that can signal the importance of taking action (for example, a neighbour who is diagnosed with the same disease or a mass media campaign). This is all about factors that trigger action. Media campaigns and effective education is perceived to have an impact in the understanding of issues of epilepsy in the society.

- Self-efficacy: The individual's confidence in his or her ability to perform and sustain the recommended behaviour with little or no help from others. Here, the individual having been educated and enlightened on knowledge about epilepsy are equipped with information on medication that helps in abating recurring seizures. Thus, the individual's confident level is boosted knowing and believing that such recommended actions provide positive results.

In describing the HBM, Pechmann (2001) in Schiavo (2007) referred to it as a "risk learning model because the goal is to teach new information about health risks and the behaviours that minimize those risks" (p. 46).

The overall premise of the HBM is that knowledge will bring change. Knowledge is brought to target audiences through an educational approach that primarily focuses on messages, channels, and spokespeople (Andreasen, 1995) in Schiavo (2007, p. 51).

Nevertheless, the major contribution of the HBM to the health communication field is its emphasis on the importance of knowledge, a necessary but not sufficient step to change.

HBM can also be used for audience-related research since it provides a useful framework to organize one's thoughts in developing an audience profile.

It seems improper for health promotion campaigns to be planned and implemented on an ad hoc basis and the application of theory to practice in interventions cannot be ignored.

In order to promote health successfully and reduce ill health, health promoters should design all interventions using theoretical concepts for successful health promotion campaigns.

In relation to the study, the public should be provided with information on the causes of epilepsy, manifestation, complications, and treatment options to increase epilepsy awareness and stigma reduction. Health trainers must be taught tools to dispel the misconceptions of epilepsy such as the possible causes and manifestation epilepsy, and what to do in a first aid emergency.

In summary, the review shows that the media is always in the front burner of health media campaigns. Nigeria has $11.5 \%$ prevalence of PWE and the NECAP-RISE Clinic campaign is a program designed to create awareness, sensitize against stigmatization and provide medical assistance for epileptic patients.

Also stigmatization which is always associated with epilepsy poses to be a barrier in patient identification and socialization. The empirical studies reveal the fact that stigmatization is usually associated with PWE in Africa and Nigeria is a candid example and this is due to sentimental and mysterious beliefs that are rooted in culture and religion.

\section{RESEARCH METHODOLOGY}

This study adopted a mixed method. The first was an in-depth interview (IDI) conducted on 30 people with epilepsy whose cases have been documented at RISE Clinic Adazi-Ani. The interviews sought to generate answers from the respondents with regard to: their exposure to media campaigns against epilepsy; their awareness of epilepsy medication and treatment; whether they are induced to seek medical help and whether they are stigmatized because of their condition in their various 
communities. Also, survey method was used to collect data from the non-epileptic individuals in Anambra state. Survey questions in the questionnaire were asked in regards to: their knowledge of epilepsy as a health condition: their exposure to media campaigns against epilepsy; whether they can identify people with epilepsy in their communities and whether they avoid physical contact with epileptic patients.

Table 2. Respondents' Questionnaire Distribution Table

\begin{tabular}{|l|l|l|}
\hline S/N & \multicolumn{1}{|c|}{ Name of Community } & \multicolumn{1}{c|}{ No of Questinnare Distributed } \\
\hline 1. & Adazi-Ani (Anambra Central) & 68 \\
\hline 2. & Alor (Anambra Central) & 68 \\
\hline 3. & Isseke (Anambra South) & 67 \\
\hline 4. & Ihiala (Anambra South) & 66 \\
\hline 5. & Awkuzu (Anambra North) & 66 \\
\hline 6. & Nnado (Anambra North) & 65 \\
\hline \multicolumn{2}{|l|}{ TOTAL } & $\mathbf{4 0 0}$ \\
\hline
\end{tabular}

Random sampling method was used in selecting the questionnaire respondents in the selected study area. This is to ensure equal probability of selecting samples for the study. Two communities in each of the 3 senatorial zones in Anambra State were randomly selected. In total, six communities were randomly selected and studied.

Copies of the questionnaire were administered to people in their respective residents of the designated communities randomly selected for the study.

\section{DAta Presentation, ANALysis AND INTERPREtation}

Also, using SPSS; data from the survey questions were analyzed and presented in tables and piecharts.

The following presents the in-depth interview in the light of the research questions.

\section{Analysis of In-depth Interview of the selected interviewees}

Analysis of In-depth Interview on the exposure to media campaigns on epilepsy, impact of media campaigns in seeking medical assistance and the societal stigmatization that epileptic patients' encounter

The Thirty patients, of whom Nineteen were males and Eleven were female, were assigned into four age groups: $16-25$ years old $(\mathrm{N}=4), 26-35$ years old $(\mathrm{N}=10), 36-45$ years old $(\mathrm{N}=13)$, and 46 and above $(\mathrm{N}=3)$. They understood the questions for the interview and were capable of expressing themselves accurately.

In the first IDI (In depth Interview), the respondent defined epilepsy as a condition whereby a person's brain undergoes what is known as neurological disorder. It affects a person's brain and neurology. He said "I don't think that the mass media has ever reported anything on epilepsy on radio, TV and newspaper." He added that when his seizure started five years ago, it was one of his uncles that referred him to see a neurologist at Nnamdi Azikiwe University Teaching Hospital, Nnewi. He had been denied access to participate in singing competition in a youth conference held at Umuahia, Abia State.

When asked about their exposure to any media campaigns on epilepsy, the second, third and fourth IDI respondents said that it is not commonly heard on the radio, and they have never seen any on TV, billboards, newspaper and health posters. The third IDI respondent said "the problem is that the fight against epilepsy is not been sensitized through the media". They further said that they are not prompted by any of these media campaigns to seek medical assistance because there is little campaign on epilepsy and that is done by their associates/relatives who always refer them to seek medical assistance whenever they see their condition.

When asked whether the people living in their communities know that they have epilepsy, they said no, because it comes with a convulsive drama that is embarrassing and they are not comfortable telling people that they have epilepsy. The fourth IDI said that on several occasions people isolate from him especially where there is a gathering and he experience seizure activity; he becomes a form of distraction to people and topic of discussion too. Finally, they added that if they are opportune, they advised that the society should help in the fight against epilepsy and stigmatization. 
In the fifth IDI, the respondent was emphatic in his response to the questions, He said that "a community's customary and cultural beliefs have an impact on the limited media campaigns about epilepsy and its treatment"; he further said he experience barriers to care; lack of social support and willingness to seek alternative medical assistance for epilepsy.

The respondents in the Sixth, Seventh and Eighth IDIs said that they have seen a RISE Clinic health poster on epilepsy and they have also been exposed to information about epilepsy by their relatives. The Seventh IDI said that people in his community know she has epilepsy, and has not been denied access to participate in both cultural and social activities in her community, although she is still faced with some negative remarks from people because of her health condition.

In the Ninth IDI, the respondent said, "I have never seen any media campaign on epilepsy except the health poster by RISE clinic and my brother told me about this clinic (RISE) and since then have been receiving treatment here." He further added that he married outside his community because he was denied access to marry in his community because of his health condition.

In the Tenth, Eleventh, Twelfth, Thirteenth and Fourteenth IDIs the interviewees said they have never come across any media campaign on epilepsy and always feel ashamed whenever they have epileptic seizures in the public, people make them to feel dejected and that leads to inferiority complex. Moreover this notion was all agreed by all the interviewees.

The respondent in the Fifteenth IDI defined epilepsy as a seizure that is hereditary from birth. He narrated one of his seizure experiences in a very sunny afternoon. He further added that it was very horrible and humiliating that day but was rescued by some people while some were afraid to come by. $\mathrm{He}$ agreed that he once heard a radio jingle about epilepsy and that prompted him to seek medical assistance in RISE clinic.

The Sixteenth, Seventeenth, Eighteenth IDIs respondents said that people are uncomfortable with them because they have epilepsy and there is little or no epilepsy campaign unlike that of HIV and Ebola diseases which is seen and heard in virtually all the media outlets.

In the Nineteenth IDI, the respondent also affirmed that there is little campaign against epilepsy; he talked about his experience as a little kid whereby parents discourage their children not to play with him, due to drooling and foaming from the mouth which is deemed to be infectious. He was referred to the clinic to seek medical assistance by his relation.

The twentieth and twenty-first IDI said that people do not believe that a person with epilepsy can be successful in his or her carrier as twenty-first IDI affirmed "I am seen as an outcast in my community because I have epilepsy and no one wants to associate with me because they believe I am possessed by evil spirits."

The twenty-second, twenty-third, twenty-fourth and twenty-fifth interviewees, agreed to have heard and seen media campaigns on epilepsy and these media campaigns prompted them to seek medical assistance especially the campaign by RISE clinic. The twenty-fifth IDI added that his relatives had in the past referred him to so many native doctors and yet there was no improvement. He further said that the community he was living before knows he has epilepsy but he is not comfortable discussing it with people. The twenty-third IDI added that people do not avoid physical contact with him but he receives insult from people because of his health condition.

The twenty-sixth IDI, responded that the last seizure he experience was at a funeral and he attracted people's attention and his family was embarrassed. When asked whether he had come across a radio jingle on epilepsy, he said yes, he heard the NECAP programme on radio, he doesn't have time to watch TV. He started receiving treatment in RISE clinic because it was announced on the radio. He said that people in his community knows he has epilepsy, and as a student he doesn't receive corporal punishment like others because of his condition. He is not comfortable telling people he has epilepsy except his relations. He also added that he had been denied access to social and cultural participation that involves physical contact in so many ways. His brother stopped him from going to visit him at Onitsha because of his health condition.

In the Twenty-seventh IDI, the respondent said that he has been maltreated and shunned from normal social interactions due to the stigma associated with epilepsy like not being able to use the same cooking utensils as others and his marriage leading to a divorce. He suggested that there should be enough media campaign on epilepsy in order to reduce all forms of stigmatization in the society. 
The Twenty- eight IDI explained that she had never heard or seen any media campaign on epilepsy and it might be because of its causative nature. She said that she seek medical assistance in RISE clinic through her relation. She recommended that there should be increase in epilepsy public awareness to help the Nigerian society understand the etiology of epilepsy and various treatment options.

The twenty-ninth IDI emphasized on the need for epilepsy awareness campaign programs to educate the society about epilepsy and to reduce the stigma associated with epilepsy. He further went on to say that he had encountered bitter seizure experience over the years.

The Thirtieth IDI said that her own seizure occurs two times in a week and because of that he isolates himself from the community, and sometimes she experience low self-esteem and humiliation too. "I am not comfortable telling people I have epilepsy because it calls for a sober reflection."

From the IDIs, all the patients with epilepsy in this study felt stigma, the severity of which varied dramatically due to different factors between cases that caused the formation, enhancement and weakening of the stigma.

\subsection{Questionnaire Response Analysis}

A total of 400 copies of the questionnaire were distributed - 68 copies were respectively allotted to Alor and Adazi-Ani on the basis of proximity to the epilepsy treatment center in Adazi-Ani; 67 questionnaires were allotted to Isseke and 66 copies were allotted to other communities. Out of 68 copies of the questionnaire distributed to residents at Alor and Adazi-Ani were all returned, 66 questionnaires out of 67 distributed at Isseke were returned. At Nando, out of 65 copies distributed, 64 were returned. All 66 copies distributed to Ihiala and Awkuzu were all returned.

The total number of copies of the questionnaire returned $(\mathrm{N}=398)$ represents 99.5 percent return rate. Against the backdrop the calculated sample of 399, using Taro Yamane's formula, this response rate was considered appreciable enough to provide the necessary data for this study.

The respondents demographic variables were determined using question items from $1-6$ in the questionnaire. The data obtained were presented in pie chart and percent tables.

\subsection{Respondents' Exposure to Media Campaign against Epilepsy}

Table 3. Respondents' Knowledge about Epilepsy

\begin{tabular}{|l|l|ll|l|}
\hline \multicolumn{1}{|c|}{ S/N } & \multicolumn{1}{c|}{ Variable } & \multicolumn{1}{c|}{ Frequency } & \multicolumn{1}{c|}{ Percent } \\
\hline 1 & No & 2 & & .5 \\
\hline 2 & Yes & 396 & 99.5 & \\
\hline & Total & 398 & & 100.0 \\
\hline
\end{tabular}

Source: Survey Data, 2015

To ascertain the number of respondents that are aware of epilepsy, table 3 shows that 396 which is 99.5 percent indicates that they have knowledge about epilepsy while 2 respondents representing 0.5 percent do not.

Table 4. Respondents' exposure to radio jingle on epilepsy

\begin{tabular}{|l|l|l|l|l|}
\hline \multicolumn{1}{|c|}{ S/N } & \multicolumn{1}{c|}{ Variable } & \multicolumn{1}{c|}{ Frequency } & \multicolumn{1}{c|}{ Percent } \\
\hline 1 & No & 213 & 53.8 & \\
\hline 2 & Yes & 183 & 46.2 \\
\hline 3 & Total & 396 & 100.0 & \\
\hline
\end{tabular}

Source: Survey Data, 2015

In answer to respondents' exposure to radio jingles, table 4 indicates that 213 (54 percent) indicated that they are not aware of jingles about epilepsy on the radio while 183 (46 percent) have heard jingles about epilepsy on the radio. This indicates that the majority of the respondents are not exposed to radio jingles on epilepsy

Table 5. Respondents' Exposure to Television

\begin{tabular}{|l|l|l|l|l|}
\hline S/N & \multicolumn{1}{|c|}{ Variable } & Frequency & \multicolumn{1}{c|}{ Percent } \\
\hline 1 & No & 249 & 63 & \\
\hline 2 & Yes & 149 & 37 & \\
\hline & Total & 398 & 100 & \\
\hline
\end{tabular}


Source: Survey Data, 2015

In emphasizing on the respondent's patterns of exposure to epilepsy information, table 5 further shows respondent's exposure to television. 249 (63 percent) indicated that they have not seen information about epilepsy on TV while 149 (37 percent) indicated that they have not. Most of the respondents here are not exposed to epilepsy information on TV.

Table 6. Respondents' Exposure to Information about Epilepsy on Billboards

\begin{tabular}{|l|l|l|l|}
\hline \multicolumn{1}{|c|}{ S/N } & \multicolumn{1}{|c|}{ Variable } & \multicolumn{1}{|c|}{ Frequency } & \multicolumn{1}{c|}{ Percent } \\
\hline 1 & No & 269 & 68 \\
\hline 2 & Yes & 129 & 32 \\
\hline & Total & 398 & 100 \\
\hline
\end{tabular}

Source: Survey Data, 2015

Health information on billboards is usually designed for audience on transit. Table 6 indicates that 129 (32 percent) have come across information on epilepsy on billboard while 269 (68 percent) have not.

Table 7. Respondents' Exposure to Newspaper/Magazine Features on Epilepsy

\begin{tabular}{|l|l|l|l|}
\hline \multicolumn{1}{|c|}{ S/N } & \multicolumn{1}{|c|}{ Variable } & \multicolumn{1}{|c|}{ Frequency } & \multicolumn{1}{c|}{ Percent } \\
\hline 1 & No & 229 & 58 \\
\hline & Yes & 169 & 42 \\
\hline & Total & 398 & 100 \\
\hline
\end{tabular}

Source: Survey Data, 2015

Newspapers and Magazines are a major source of information to the audience but Table 7 depicts that 229 (58 percent) have not seen information about epilepsy on newspaper or magazines while 169 (42 percent) indicated positive.

Table 8. Respondents' Exposure to Information about Epilepsy on Health Posters/Fliers

\begin{tabular}{|l|l|l|l|}
\hline \multicolumn{1}{|c|}{ S/N } & \multicolumn{1}{|c|}{ Variable } & \multicolumn{1}{c|}{ Frequency } & \multicolumn{1}{c|}{ Percent } \\
\hline 1 & No & 212 & 53 \\
\hline & Yes & 185 & 47 \\
\hline & Total & 397 & 100 \\
\hline
\end{tabular}

Source: Survey Data, 2015

Bylines such as posters and flyers are one of the handy and potent ways of disseminating health information. Table 8 shows that 212 (53 percent) are not exposed to information about epilepsy on health posters/fliers while 185 (47 percent) indicated positive to the question.

Table 9. Respondents' Knowledge about Epilepsy through Relatives or Associates

\begin{tabular}{|l|l|l|l|}
\hline \multicolumn{1}{|c|}{ S/N } & \multicolumn{1}{|c|}{ Variable } & \multicolumn{1}{|c|}{ Frequency } & Percent \\
\hline 1 & No & 137 & 35 \\
\hline 2 & Yes & 260 & 65 \\
\hline & Total & 398 & 100 \\
\hline
\end{tabular}

\section{Source: Survey Data, 2015}

Interpersonal communication is buzz sources through which health information is transferred. Table 9 shows that 260 (65 percent) heard information about epilepsy through their relatives/friends or associates while137 (35 percent) indicted negative. Here the majority of the respondents agreed that they get information about epilepsy through their relations or associates.

\subsection{Respondents' Understanding of Epilepsy through Media Campaign}

Table 10. Respondents' Response to Understanding of Promotional Radio Jingles on Epilepsy

\begin{tabular}{|l|l|l|l|}
\hline \multicolumn{1}{|c|}{ S/N } & \multicolumn{1}{|c|}{ Variable } & \multicolumn{1}{|c|}{ Frequency } & \multicolumn{1}{c|}{ Percent } \\
\hline 1 & No & 284 & 71 \\
\hline 2 & Yes & 112 & 28 \\
\hline 3 & Don't Know & 2 & 1 \\
\hline & Total & 398 & 100 \\
\hline
\end{tabular}

Source: Survey Data, 2015 
Table 10 shows that respondents that understand promotional radio jingles about epilepsy on their radio constitute 28 percent; 71 percent do not understand it while $1 \%$ does not know whether they understand promotional radio jingles on epilepsy.

Table 11. Respondents' Response to Understanding of Promotional TV Programmes on Epilepsy

\begin{tabular}{|l|l|l|l|}
\hline \multicolumn{1}{|c|}{ S/N } & \multicolumn{1}{|c|}{ Variable } & \multicolumn{1}{|c|}{ Frequency } & \multicolumn{1}{c|}{ Percent } \\
\hline 1 & No & 278 & 70 \\
\hline 2 & Yes & 118 & 30 \\
\hline 3 & Don't know & 2 & 0.5 \\
\hline & Total & 398 & 100 \\
\hline
\end{tabular}

Source: Survey Data, 2015

Most people believe and understand information when they are been displayed on the television Table 15 depicts that 278 (70 percent) do not understand promotional TV jingles about epilepsy; 30 percent indicated that they understand it while 0.5 indicated that they don't know.

Table 12. Respondents' Responses to Understanding of Epilepsy Information on Billboards

\begin{tabular}{|l|l|l|l|}
\hline \multicolumn{1}{|c|}{ S/N } & \multicolumn{1}{|c|}{ Variable } & \multicolumn{1}{|c|}{ Frequency } & \multicolumn{1}{c|}{ Percent } \\
\hline 1 & No & 301 & 76 \\
\hline 3 & Yes & 94 & 23 \\
\hline & Don't know & 3 & 1 \\
\hline
\end{tabular}

Source: Survey Data, 2015

Table 12 shows that 301 (76 percent) do not understand information about epilepsy on billboards; 94 (23 percent) of the respondents indicated positive while 3 (1\%) shows that they don't know.

Table 13. Respondents' Response to Understanding of Newspaper/Magazine Features on Epilepsy

\begin{tabular}{|l|l|l|l|}
\hline \multicolumn{1}{|c|}{ S/N } & \multicolumn{1}{|c|}{ Variable } & \multicolumn{1}{c|}{ Frequency } & \multicolumn{1}{c|}{ Percent } \\
\hline 1 & No & 241 & 61 \\
\hline 3 & Yes & 155 & 39 \\
\hline & Don't know & 2 & 0.5 \\
\hline
\end{tabular}

Source: Survey Data, 2015

Table 13 indicates that 241 (61 percent) do not understand newspaper/magazine features on epilepsy; 155 (39 percent) of the respondents understands while 0.5 percent do not know.

Table 14. Respondents' response to understanding of health posters/fliers on epilepsy

\begin{tabular}{|l|l|l|l|}
\hline \multicolumn{1}{|c|}{ S/N } & \multicolumn{1}{|c|}{ Variable } & \multicolumn{1}{|c|}{ Frequency } & \multicolumn{1}{c|}{ Percent } \\
\hline 1 & No & 229 & 58 \\
\hline 2 & Yes & 165 & 41 \\
\hline 3 & Don't know & 4 & 1 \\
\hline & Total & 398 & 100 \\
\hline
\end{tabular}

Source: Survey Data, 2015

Table 14 states that 229 (58 percent) do not understand information about epilepsy on health posters while 165 (41 percent) of the respondents do understand them. In addition, 4 ( 1 percent) indicated that they do not know.

Table 15. Respondents' response to understanding of epilepsy through associates/relatives

\begin{tabular}{|l|l|l|l|}
\hline S/N & \multicolumn{1}{|c|}{ Variable } & \multicolumn{1}{c|}{ Frequency } & Percent \\
\hline 1 & No & 145 & 36 \\
\hline 2 & Yes & 253 & 64 \\
\hline & Total & 398 & 100 \\
\hline
\end{tabular}

Source: Survey Data, 2015

As explained earlier, interpersonal communication is a vital source of influence. Table 15 indicates that $253(64 \%)$ understand information about epilepsy through friends, relatives or associates while $36 \%$ does not. This indicates that word of mouth or face to face communication is an effective way of sharing meanings and ideas to the society. 
Epilepsy, Stigmatization and Media Campaigns: An Assessment of Rise Clinic Experience

\subsection{Respondents' Knowledge of Epileptic Patients}

Table 16. Respondents' response to knowledge of epileptic patients

\begin{tabular}{|l|l|l|l|}
\hline \multicolumn{1}{|c|}{ S/N } & \multicolumn{1}{|c|}{ Variable } & \multicolumn{1}{|c|}{ Frequency } & Percent \\
\hline 1 & No & 104 & 26 \\
\hline 2 & Yes & 293 & 74 \\
\hline & Total & 397 & 100 \\
\hline
\end{tabular}

Source: Survey Data, 2015

The analysis in table 16 shows that 104 (26 percent) indicated that they have not seen or have any knowledge of a person suffering from epilepsy while 293 (74 percent) shows that they have knowledge of person suffering from epilepsy.

Table 17. Respondents' Response to Seizure Activities by Epileptic Patients

\begin{tabular}{|l|l|l|l|}
\hline \multicolumn{1}{|c|}{ S/N } & \multicolumn{1}{|c|}{ Variable } & \multicolumn{1}{c|}{ Frequency } & Percent \\
\hline 1 & No & 203 & 49 \\
\hline 2 & Yes & 195 & 51 \\
\hline & Total & 398 & 100 \\
\hline
\end{tabular}

Source: Survey Data, 2015

Table 17 indicated that 90 (23 percent) has not witness seizures by epileptic patients while 308 (77 percent) have.

\subsection{Respondents' Attitude towards Epileptic Patients in their Community}

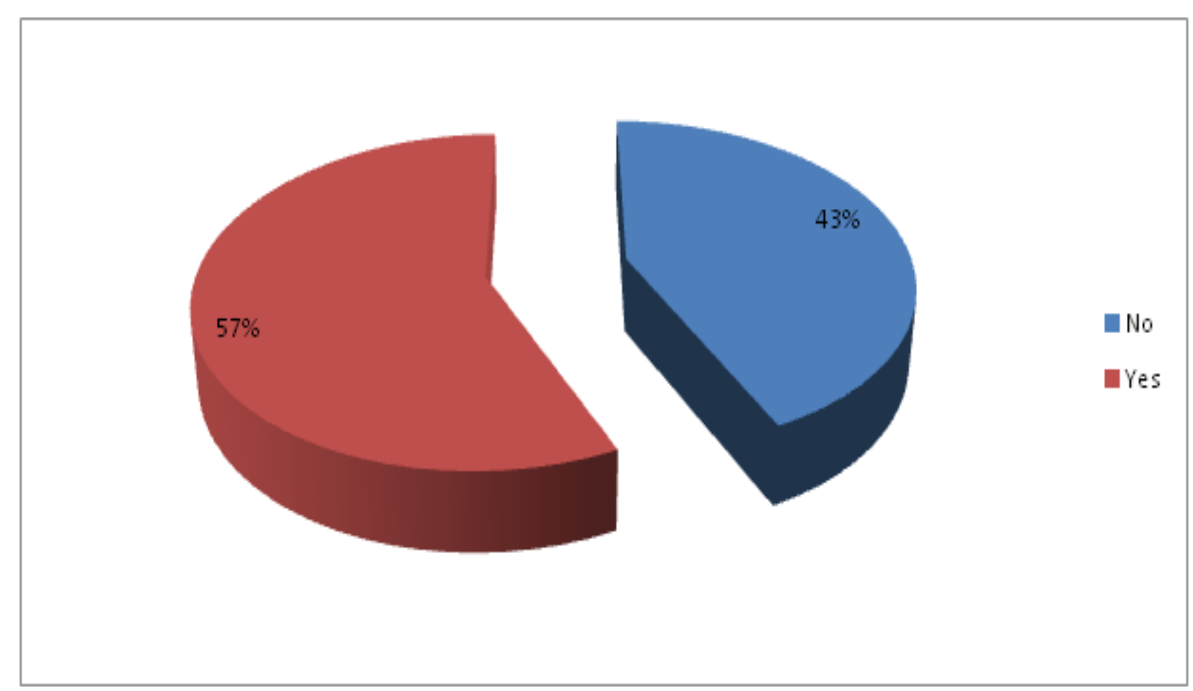

Figure 1. Respondents' Response to Segregation among Epileptic Patients

In Figure 1, it was discovered that 169 (43 percent) do not segregate or stigmatize against epileptic patients while 228 (57 percent) do.

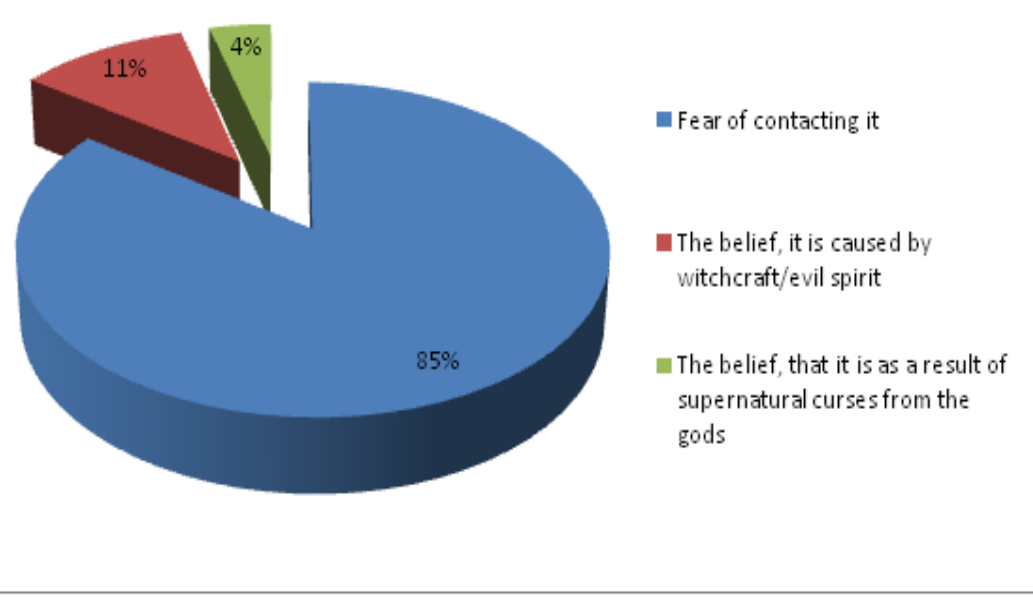

Figure 3. Respondents' Response to Reason for Segregation among Epileptic Patients 
Source: Survey Data, 2015

Figure 3 represents that out of those that stigmatize against epileptic patients, 25 (11 percent) believe that it is cause by witchcraft/evil spirit while 9 (4 percent) believe that it is as a result of supernatural curses from the gods, while 85 percent fears that they will contact the disease when they have physical contact with an epileptic patient.

This confirms the assumption that understanding of epilepsy is beclouded with baseless spiritual belief that it is a punishment from the gods.

Table 18. Respondents' Response to Stigmatization of People with Epilepsy by Society

\begin{tabular}{|l|l|l|l|}
\hline \multicolumn{1}{|c|}{ S/N } & \multicolumn{1}{|c|}{ Variable } & \multicolumn{1}{c|}{ Prequency } & \multicolumn{1}{|c|}{ Percent } \\
\hline 1 & No & 126 & 32 \\
\hline 2 & Yes & 272 & 68 \\
\hline & Total & 398 & 100 \\
\hline
\end{tabular}

Source: Survey Data, 2015

In table 18, it shows that $126(32 \%)$ of the sample do not believe that people with epilepsy are maltreated in the society while $272(68 \%)$ do believe that people with epilepsy are treated unfairly in the society.

\section{RESEARCH QUESTIONS AND DISCUSSION OF FINDINGS}

The study has five specific objectives: 1) to ascertain if epileptic patients are exposed to media campaigns against epilepsy; 2)to find out if any non-epileptic members of the public is exposed to media campaigns against epilepsy; 3)to determine if exposure to media campaigns against epilepsy induce epileptic patients to seek medical help; 4)to ascertain if exposure to media campaigns against epilepsy improves the understanding of the issue of epilepsy among non-epileptic members of the public; 5)to ascertain if there is societal stigmatization against epileptic patients.

\subsection{Analysis of Research Questions}

The study included IDI from thirty respondents. The purpose of the interview is to clarify research questions 1,2 and 5 which are about patterns of exposure to media campaigns on epilepsy, impact of media campaigns in seeking medical assistance and forms of societal stigmatization against people with epilepsy. The results as presented in 4.1 suggest that the thirty interviewees agreed that there are little or no media campaigns on epilepsy and the interview recorded cases of stigmatization against them in their various communities. Most of the respondents agreed that they are been prompted by their associates and relations to seek medical assistance.

The data analyzed in this study was obtained from 398 respondents spread across six communities in 3 senatorial zones - Anambra North, Anambra Central and Anambra South. The overall results offer a wide range of conclusions.

In table 3, it is prominent that respondents know about epilepsy. This prominence amounts to $99.5 \%$ against $0.5 \%$ who does not.

In the rural areas, the radio is one of the most prominent sources of information. Table 4 indicates that $213(54 \%)$ indicated that they are not aware of jingles about epilepsy on the radio while $183(46 \%)$ have heard jingles about epilepsy on the radio.

Table 5 suggests that television is not effective medium of health communication in the rural area hence only $37 \%$ were exposed to media campaign about epilepsy through the TV.

Health information on billboards is usually designed for audience on transit. Table 6 indicates that only $32 \%$ have come across information on epilepsy on billboard. This is affirmed by Lancet (2010) who opines that "exposure to such messages is generally passive, resulting from an incidental effect of routine use of media" (p. 3). Also in the same vein, newspaper/magazine and health posters constitutes $58 \%$ and $53 \%$ of respondents who are not exposed to such media for health information on epilepsy.

It is likely that most health information is transferred through Interpersonal sources. Table 15 shows that $65 \%$ of the respondents heard information about epilepsy through their relatives/friends against 
$35 \%$ that indicted negative. This shows that there is need for awareness campaign to create knowledge about epilepsy and to sensitize people against stigmatization of epileptic patients.

In section 4.5 , it elucidates the response to understanding of epilepsy campaigns by the media. Table $10,11,12,13,14$ and 15 shows that health information about epilepsy received through the radio, television, newspaper/magazine and health posters are not well diffused or understood. Rather, information about epilepsy is well understood through friends/associated as $65 \%$ indicated in Table 19.

In section 4.6, it presents the respondents' knowledge of epileptic patients. $74 \%$ indicated that they know an epileptic patient. While 51\% has witnessed seizure of an epileptic patient.

In response to section 4.7, 3 questions were designed to ascertain respondents' attitude towards epileptic patients in their community. It was discovered that the majority of the respondents engages in societal stigmatization against people with epilepsy.

Stigma is a major obstacle in the care for epileptic patients and that represents an overwhelming proportion of the psychosocial burden of epileptic patient. Stigma against epileptic patients knows no boundaries and occurs across all ethnic, gender, educational, and socioeconomic groups, leading to discrimination. According to (Baskind \& Brubeck (2005), "Only by frequent, rapid, repetitive, and effective education and the recognition and reconciliation of institutionalized stigma can the downward spiral of epilepsy be reversed. Stigma and social discrimination in relation to epilepsy may be associated with a lack of knowledge and understanding about the condition".

Atadzhanov, Haworth, Chomba, Mbewe, Birbeck (2010) revealed that:

In Zambia, several studies were done among different groups of people (teachers, clerics, policemen, traditional healers, and health workers) to describe their knowledge of epilepsy and attitude to PWE.8, 10, 17-20 In general these studies showed a lack of knowledge regarding causes and treatment. There are not many studies examining the effect of education on stigma (p. 6).

Figure 2 represents that out of those that stigmatize against epileptic patients, 25 (11\%) believe that it is cause by witchcraft/evil spirit while $9(4 \%)$ believe that it is as a result of supernatural curses from the gods. While in table 22, it shows that $126(32 \%)$ of the sample do not believe that people with epilepsy are maltreated in the society while $272(68 \%)$ do believe that people with epilepsy are treated unfairly in the society.

\section{CONCLUSION AND RECOMMENDATION}

The general purpose of this study was to ascertain the level of knowledge about epilepsy, establish the patterns of media exposure; understanding of media information on epilepsy and to establish stigmatization of epileptic patients in our society.

The survey research method was adopted for this study. Data was collected in 6 communities - AdaziAni, Alor, Isseke, Ihiala, Awkuzu and Nando by administering questionnaire to a sample of 400 .

This study found that media campaign on epilepsy is insufficient hence the stigmatization of epileptic patients in their communities. Also, $86 \%$ of respondents believe that they can contract epilepsy by merely touching an epileptic patient.

This study used triangulation method of in-depth interviews and selected survey questions to establish respondents' knowledge; media exposure; understanding of information about epilepsy and attitude of stigmatization against epileptic patients.

The major finding of the study suggests that most of the respondents are not exposed to any pattern of media campaigns against epilepsy. However, respondents get information about epilepsy through associates/relative. In analyzing understanding of epilepsy through media campaign, it was discovered that there is poor diffusion of information about epilepsy as presented in the media. Also, majority of the respondents indicated that epilepsy is contagious through contacted fluids from an epileptic patient.

Health information is very vital in addressing health issues. Health crisis like Ebola and HIV receives more information because of its danger to public health. The backbone of health campaign is the 
media which is a vehicle of driving home health campaigns to influence health decisions and change attitudes. This is in tandem with Clansey (2004) in Schiavo (2007, p. 7) who defined Health communication as "the main currency of health care in this $21^{\text {st }}$ century".

Due to time and manpower constraints, only 400 respondents were surveyed and this must be kept in mind when percentages were considered. Also, because of the narrow scope of the survey, the findings of this current study cannot be generalised to the Nigerian population. It would be ideal if a larger number of respondents were sampled in future research.

This study also examines the effectiveness of NECAP-RISE clinic campaign against epilepsy to evaluate the impact of the campaign on the public by studying the randomly selected communities across the 3 senatorial zones.

The findings lead to the conclusion that there is need for increase in media campaign against epilepsy in Nigeria.

\section{RECOMMENDATIONS}

In this study, measures were implemented to determine people's responsiveness to media campaigns on epilepsy. These factors were considered

- patterns of exposure to media campaigns on epilepsy

- impact of media campaigns in seeking medical assistance

- impact of media campaign in improving the understanding of the issue of epilepsy

- forms of societal stigmatization against people with epilepsy

Actions needed to improve public awareness, knowledge and media campaigns on epilepsy include informing journalists as well as writers and producers in the entertainment industry; engaging people with epilepsy and their families in public awareness efforts; coordinating public awareness efforts and developing shared messaging; and ensuring that all campaigns include rigorous formative research, considerations for health literacy and audience demographics, and mechanisms for evaluation and sustainability.

This study has revealed that ignorance and illiteracy affect people's attitudes towards people with epilepsy. And such attitudes are usually negative and stigmatizing. Therefore, to make the society a better place for people with epilepsy, there is an urgent need for public education and enlightenment.

A better understanding of the disorder among the public would allay fears and mistrust about people with epilepsy in the community as well as lessen stigmatization towards such persons. Therefore, the government should launch Information Education Communication (IEC) programs to teach the community on the causes, symptoms, first aids and the roles of people with epileptic health conditions in the society.

People with epilepsy should be encouraged to be compliant with their medication because this will help in seizure control, thus reducing stigma and improving their quality of life.

The government should organize outreach programmes for various communities in order to reduce the level of stigmatization in the society

\section{REFERNCES}

[1] Akinsulore A, \& Adewuya A (2010). Psychosocial aspects of epilepsy in Nigeria. African Journal of Psychiatry 78 (4), 394-412.

[2] Atadzhanov, M., Haworth, A., Chomba, E., Mbewe, E., \& Birbeck, G. (2010). Epilepsy associated stigma in Zambia: What factors predict greater felt stigma in a highly stigmatized population? Epilepsy \& Behavior. 19(3): 414-816

[3] Bandstra, N.-F., Camfield, C., \& Camfield, P. (2008). Stigma of epilepsy: Canadian Journal of Neurological Sciences. 35(4), 436-440.

[4] Baskind, R., \& Brubeck, G.L., (2005). Epilepsy-associated stigma in sub-Saharan Africa: The social landscape of a disease. Epilepsy Behave 7, 68-73.

[5] Bateman, L., Begley, C., Ben-Menachem, E., Berg, A., Berkovic, S., Cascino, G., Drazkowski, J., Edwards, J., Engel, J., French, J., Gilliam, F., Hoerth, M., Jehi, L., Kanner, A., Krauss, G., Labiner, D., 
Loddenkemper, T., Luders, H., McKhann, I., McLachlan, R., Modi, A., Pennell, P., Shafer, Sirven, J., Stern, J., Szaflarski, J., and William H. Theodore (2012). Epilepsy Currents: Overcoming Barriers to Successful Epilepsy Society. USA. Allen Press.

[6] Berhanu, S., Alemu, S., Prevett, M., \& Parry, E. (2009). Primary care treatment of epilepsy in rural Ethiopia: causes of default from follow-up. Seizure, 18(2): 100-313.

[7] Center for Disease Control and Prevention (2011) Clifton Rd. Atlanta, GA 30329-4027, USA. 800-CDCINFO (800-232-4636) TTY: (888) 232-6348-Contact CDC-INFO

[8] Center for Disease control and prevention (2013) Clifton Rd. Atlanta, GA 30333, USA, 800-CDC-INFO (800-232-4636) TTY: (888) 232-6348-Contact CDC-INFO

[9] Epilepsy Foundation (2010). Proposal for revised clinical and electroencephalographic classification of epileptic seizures. From the Commission on Classification and Terminology of the International League Against Epilepsy. Epilepsia, 22, 489-501.

[10] Fisher, R., Boas, W., Blume, W., Elger, C., Genton, P., Lee, P., \& Engel Jr., (2005) Epileptic seizure and epilepsy: definitions proposed by the International League Against Epilepsy(ILAE) and the International Bureau for Epilepsy (IBE). Epilepsia 46(4): 470-2. Doi:10.111/j.0013-9580.2005.66104.x. PMID 15816939.

[11] French, J. (2004) Components of successful media campaigns. HDA Briefing Paper: Health Development Agency, in press (available from jeff.french @ had-online.org.uk).

[12] Halpern and Bates (2004). Personality responsibility and changing behaviour: the state of knowledge and its implications for public policy. London: Cabinet office, Prime Minister's Strategy Unit. www.strategy.gov.uk /files/pdf/pr.pdf

[13] Hills, M. D., \& Mackenzie, H. C. (2004). New Zealand community attitudes toward people with epilepsy. Epilepsia, 43(12), 1583-1589. .

[14] ILAE/IBE/WHO (2011) Global Campaign Against Epilepsy. Netherland. Global Campaign Secretariat.

[15] Kabir, lliyasa, Abu-Bakr, Kabir, \& Farinyaro, 2005. The relative impact of anxiety, depression, and clinical seizure features on health related quality of life in epilepsy. Epilepsia 45:544-550.

[16] Kristin, W. (2012). Epilepsy Niagara: Niagara Falls, Ontario L2E 4C9.

[17] Lancet Neurology (2010), volume 9, issue 10, page 941, doi: 10/6/S/474-4422(10)70226-X. South Africa. Reed Elseiver Properties.

[18] Maduakor-Ugo, A. C. (2014) Effect of Education on Stigma of Epilepsy in South Eastern Nigeria (Phd Dissertation, Walden University, Minneapolis, Minnesota, USA) Retrieved from http://pqdtopen.proquest.com/pqdtopen/doc/1534363421.html?FMT=ABS

[19] Mbuba C.K, Ngugi A.K, Newton C.R, Carter J.A (2008). The epilepsy treatment gap in developing countries: A systematic review of the magnitude, causes, and intervention $\quad$ strategies. Epilepsia: 49(9): 1491-503.

[20] Nigeriamasterweb.com (2014). The 2006 population census. Accessed from http//www.nigeriamasterweb.com/Nigeria2006censusfigs.html on 17 August, 2014.

[21] Oarhe, O., \& Aghedo, I. (2010). The open sore of a nation: Corruption complex and internal security in Nigeria. African Security, 3(3), 127-147.

[22] Olubunni, A. (2006). Epilepsy in Nigeria: A review of etiology, epidemiology and management. Benin Journal of Post-graduate Medicine, 8(1), 27-41.

[23] Pahl, K., \& Boer, H., (2005): Epilepsy and rights. In: Atlas: Epilepsy Care in the world.Geneva:WHO.p.72-3.

[24] Paschal, A.-M., Hawley, R., Romaine, S., Low, K., Mudguard, C. A., Sly, J., \& Sadler, T. L. (2007). Epilepsy patients' perceptions about stigma, education, and awareness: Preliminary responses based on a community participatory approach. Epilepsy \& Behavior, 11(3), 329-337.

[25] Petrova, L. D. (2011). Tuberous sclerosis and epilepsy. American Journal of Electroneurodiagnostic Technology, 51(1), 5-15

[26] Preux, P.-M., \& Druet-Cabanac, M. (2005). Epidemiology and etiology of epilepsy in sub-Saharan Africa. Lancet Neurology, 4(1), 21-31.

[27] Scambler and Hopkins (2006) Being epileptic: coming to terms with stigma, Academic Department of Psychiatry Middlesex Hospital Medical School London W1P8AA, U.K.

[28] Schiavo, R. (2007). Health Communication: From Theory to Practice. (first edition) San Francisco: John Wiley \& Sons, Inc.

[29] Schneider, J. \& Conrad, P. (2009) 'Medical and sociological typologies: the case of epilepsy. Social Science \& Medicine 15A 211-219. 
[30] Shibre, T., Alem, A., \& Tekle-Haimanot, R. (2008). Community attitudes towards epilepsy in a rural Ethiopian setting: a re-visit after 15 years. Ethiop Med J 2008; 46(3): 2519.

[31] Singh, P. (2011). Infectious causes of seizures and epilepsy in the developing world. Developmental Medicine \& Child Neurology, 53(7), 600-609.

[32] Sparks, O. (2012). Mass media campaign in promoting health communication. Accessed from www.healthresearchforaction.org. September, 212013.

[33] Tellez-Zen ten, J., Pondal-Sordo, M., Matijevic, S., \& Wiebe, S. (2004). National and regional prevalence of self-reported epilepsy in Canada. Epilepsia 45(12): 1623-9.

[34] Tones, K and Green, J (2004). Health Promotion: planning and Strategies, (2 ${ }^{\text {nd }}$ ed). London: Sage Publisher.

[35] Udoh, C. C. (2006). Pattern and presentation of epilepsy, a study of trends in the Nigeria Teaching Hospital, Enugu. University of Ilorin, Nigeria.

[36] Weiss, B. (2005). Epidemiology of health literacy. In J. G. Schwartzberg, J. B. VanGeest, \& C. C. Wang (Eds), Understanding health literacy: implications for medicine and public health. American Medical Association, AMA Press, pp. 17-40.

[37] World Health Organization. (2004). Epilepsy in the WHO African region. Bridging the gap, epilepsy out of the shadow.

[38] World Health Organization. (2005). Atlas: Epilepsy care in the world. Geneva, Switzerland: Author. 